\title{
PROPAGAÇÃO VEGETATIVA DE CEDRO-ROSA POR MINIESTAQUIA ${ }^{1}$
}

\author{
Aloisio Xavierr2, Glêison Augusto dos Santos² Ivar Wendling² e Marcelo Lelis de Oliveira² $^{2}$
}

\begin{abstract}
RESUMO - O objetivo deste trabalho foi avaliar a técnica de miniestaquia como método de propagação vegetativa de cedro-rosa (Cedrela fissilis), quanto à produção e sobrevivência das minicepas nas sucessivas coletas e quanto ao porcentual de enraizamento e do crescimento em altura e diâmetro do colo das miniestacas. As minicepas foram obtidas a partir de mudas de sementes de cedro-rosa, das quais promoveram-se as coletas sucessivas de miniestacas, sendo essas submetidas a diferentes dosagens do regulador de crescimento AIB para enraizamento. Os resultados demonstraram a eficiência da técnica na propagação vegetativa desta espécie, atingindo-se até $79 \%$ de sobrevivência aos 120 dias de idade das mudas, devendo-se destacar que a não-aplicação do AIB proporcionou melhores resultados. Em termos gerais, a miniestaquia de cedro-rosa, a partir de material de origem seminal, é tecnicamente viável, tornando-se uma alternativa para produção de mudas dessa espécie durante todo o ano, principalmente nas situações em que a semente é insumo limitante.
\end{abstract}

Palavras-chave: Cedrela fissilis, enraizamento e propagação de plantas.

\section{VEGETATIVE PROPAGATION OF CEDRO-ROSA BY MINICUTTING}

\begin{abstract}
This work had the objective to evaluate the minicutting technique as a method for vegetative propagation of cedro-rosa (Cedrela fissilis), in terms of the production and survival of the ministumps after successive harvesting, as well as rooting and growth (height and root collar diameter) of the minicuttings. The minicuttings were obtained from seedlings of Cedrela fissilis, successively collected and submitted to different dosages of the growth regulator IBA. The results showed the efficiency of this technique in the vegetative propagation of this species. Up to 79\% survival was obtained at 120 days of age, but when IBA was not applied, survival was higher. Overall, minicutting of Cedrela fissilis from material of seminal origin is technically viable. Its is an alternative method for producing seedlings of this species throughout the year, mainly when seeds are unavailable.
\end{abstract}

Key words: $\quad$ Cedrela fissilis, rooting and plant propagation.

\section{INTRODUÇÃO}

Dentre as inúmeras espécies florestais nativas do Brasil de alto valor econômico tem-se o cedro-rosa (Cedrela fissilis Vell.), devido à sua larga utilização para os mais diversos fins. No entanto, informações sobre processos de produção de mudas por propagação vegetativa e posterior estabelecimento de plantios comerciais dessa espécie são escassas na literatura.

O uso econômico da propagação vegetativa na produção de mudas para o setor florestal é justificado quando há disponibilidade de genótipos de alta produtividade e, ou, a semente é insumo limitado. Nestas condições, muitas espécies nativas, dentre elas o cedrorosa, possuem restrições na obtenção de sementes durante todo o ano, portanto sua propagação vegetativa pode ser uma alternativa viável.

Dentre os processos de propagação vegetativa, a miniestaquia é uma técnica recente que vem sendo utilizada com sucesso na maximização do processo de propagação clonal em Eucalyptus, que surgiu a partir do aprimoramento da estaquia, visando contornar as

1 Recebido para publicação em 31.7.2001.

Aceito para publicação em 19.2.2003.

2 Departamento de Engenharia Florestal da Universidade Federal de Viçosa - UFV, 36571-000 Viçosa, Minas Gerais, Brasil. 
dificuldades de enraizamento de alguns clones (Xavier $\&$ Wendling, 1998; Wendling et al., 2000). Dentre as vantagens da miniestaquia em relação à estaquia, podem-se citar a redução da área necessária para formação do jardim miniclonal, por localizar-se em bandejas no próprio viveiro; redução dos custos com transporte e coleta das brotações; maior eficiência das atividades de manejo no jardim miniclonal (irrigação, nutrição, manutenções e controle de pragas e doenças), além de proporcionar maior qualidade, velocidade e porcentual de enraizamento das miniestacas.

No entanto, pouco ou quase nada se conhece sobre a miniestaquia como técnica de propagação vegetativa em aplicação nas espécies florestais nativas, tanto em nível experimental quanto comercial. Resultados iniciais obtidos por Santos et al. (2000), por exemplo, apontaram a viabilidade técnica da propagação vegetativa por miniestaquia na produção de mudas de jequitibá-rosa (Cariniana estrellensis), sete-cascas (Samanea inopinata) e, principalmente, para o mogno (Swietenia macrophylla).

Dessa forma, a avaliação da eficiência da miniestaquia em cedro-rosa contribuirá para a ampliação dos conhecimentos dos processos de produção de mudas desta espécie, suportando a base para uma silvicultura clonal para fins comerciais e gerando mais um aporte econômico para o País.

Com base no exposto, o objetivo deste trabalho foi avaliar a viabilidade da técnica de miniestaquia na propagação clonal de cedro-rosa (Cedrela fissilis) quanto à produção e sobrevivência das minicepas nas sucessivas coletas e no enraizamento e crescimento em altura e em diâmetro do colo das miniestacas provenientes das sucessivas coletas no jardim miniclonal, submetidas a diferentes dosagens do regulador de crescimento AIB $(0,1.000,2.000$ e $4.000 \mathrm{mg} / \mathrm{l})$.

\section{MATERIAL E MÉTODOS}

O presente trabalho foi realizado no viveiro de pesquisas florestais do Departamento de Engenharia Florestal da Universidade Federal de Viçosa, Viçosa-MG. As mudas de cedro-rosa (Cedrela fissilis) foram produzidas a partir de sementes, em tubetes plásticos de $200 \mathrm{~cm}^{3}$, contendo substrato formado pela mistura de composto orgânico ( $80 \%)$ e moinha de carvão (20\%).

Ao atingirem altura média de $15 \mathrm{~cm}$, as mudas foram transferidas para casa de sombra com $50 \%$ da luz natural, visando obter condições ecológicas propícias para seu melhor crescimento, e em seguida decepou-se a parte aérea, a uma altura de $10 \mathrm{~cm}$ da base, para estimular as brotações nas minicepas, formando o jardim miniclonal, conforme procedimentos da técnica descrita por Xavier \& Wendling (1998).

O jardim miniclonal foi composto por 100 minicepas, onde efetuaram-se adubações semanais com macro e micronutrientes e irrigação, visando o crescimento vegetativo. Em períodos regulares de 30 dias, as minicepas proporcionaram miniestacas com tamanho entre 4 e $6 \mathrm{~cm}$, contendo de um a três pares de folhas, reduzidas a $25 \%$ de seu tamanho original.

Imediatamente após coletadas e preparadas, as miniestacas foram estaqueadas em casa de vegetação climatizada, com umidade relativa do ar superior a $85 \%$ e temperatura média de $25^{\circ} \mathrm{C}$. Como recipientes, foram utilizados tubetes plásticos de $55 \mathrm{~cm}^{3}$, contendo substrato formado pela mistura de vermiculita de granulometria média (30\%) e composto orgânico $(70 \%)$. O tempo de permanência das miniestacas em casa de vegetação foi de 50 dias, sendo posteriormente aclimatadas em casa de sombra com $50 \%$ de sombreamento durante dez dias e transferidas para área de pleno sol, com redução de $25 \%$ da luz natural, para sua rustificação. Na Figura 1 é apresentado o esquema de miniestaquia utilizado no presente estudo para cedro-rosa.

Foram avaliados quatro tratamentos referentes ao regulador de crescimento para enraizamento, constituídos pela aplicação das dosagens de $0,1.000,2.000 \mathrm{e}$ $4.000 \mathrm{mg} / \mathrm{l}$ de AIB (ácido indolbutírico), via líquida na base da miniestaca, durante 5 segundos.

A nutrição das miniestacas foi composta por macro e micronutrientes $\left(\mathrm{N}\right.$ total $=15 \%, \mathrm{P}_{2} \mathrm{O}_{5}=15 \%, \mathrm{~K}_{2} \mathrm{O}=$ $20 \%, \mathrm{Ca}=1,1 \%, \mathrm{~S}=4 \%, \mathrm{Mg}=0,4 \%, \mathrm{Zn}=0,05 \%, \mathrm{~B}=$ $0,05 \%, \mathrm{Fe}=0,1 \%$ e $\mathrm{Mn}=0,03 \%$ ), aplicada parceladamente na dosagem de $0,05 \mathrm{~g}$ por planta, uma vez por semana. A irrigação e os tratos silviculturais foram os necessários à obtenção do crescimento vigoroso das mudas.

O delineamento experimental utilizado foi o inteiramente casualizado, com quatro repetições e 24 miniestacas por parcela. As avaliações realizadas foram quanto à produção e à sobrevivência das minicepas em quatro coletas sucessivas e quanto ao porcentual de enraizamento e do crescimento em altura e diâmetro do colo das miniestacas aos 120 dias de idade. 

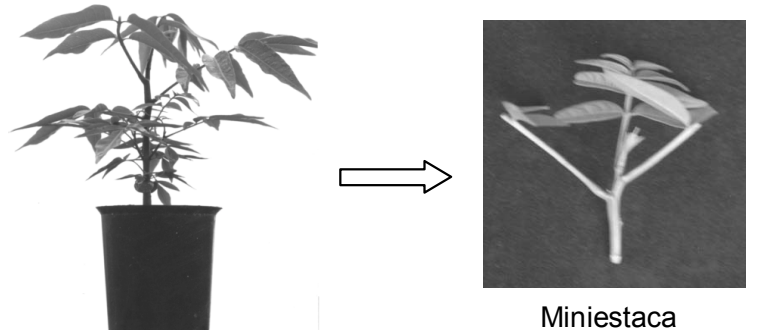

Minicepa
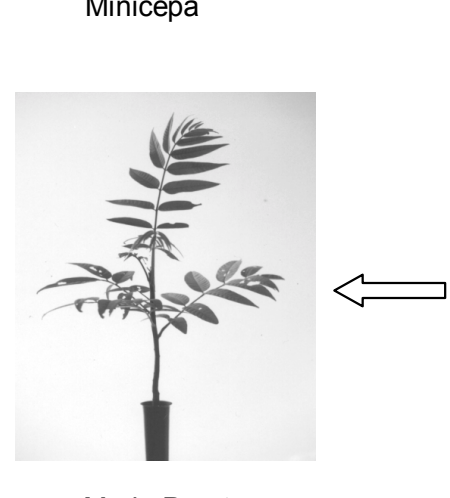

Muda Pronta

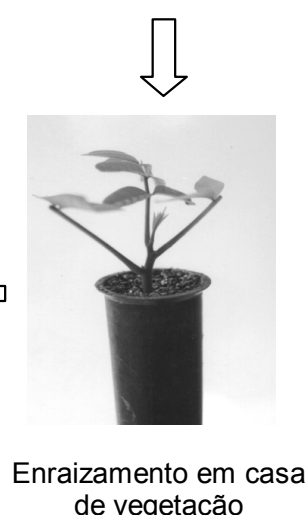
de vegetação

Figura 1 - Esquema do processo de miniestaquia de cedrorosa (Cedrela fissilis).

Figure 1 - Illustrative model of minicutting technique used for vegetative propagation of cedro-rosa (Cedrela fissilis).

\section{RESULTADOS E DISCUSSÕES}

As quatro coletas sucessivas de miniestacas não afetaram a sobrevivência das minicepas, uma vez que não foi registrada mortalidade nesse período. Essa sobrevivência denota a adequabilidade dos tratos culturais empregados, como nutrição equilibrada, irrigação em níveis ótimos e bom manejo de condução das minicepas. Este fato está de acordo com o relatado por Blazich (1987) e Hartmann et al. (1997), que constataram que, entre os fatores que afetam a propagação vegetativa, a nutrição e o status hídrico são de fundamental importância na manutenção do vigor da planta-mãe, o que irá refletir na quantidade e qualidade dos propágulos vegetativos, bem como no seu potencial de regeneração.

Obteve-se uma produtividade média de 1,3 miniestaca por minicepa por coleta (Figura 2), o que indica a habilidade e a capacidade de produção de novas brotações das minicepas após cada coleta de miniestacas. Estes dados encontram-se muito próximos aos relatados para Eucalyptus por Wendling et al. (2000), que foi em torno

de 1,7 miniestaca por minicepa por coleta. A menor produtividade observada na primeira coleta foi decorrente do fato de a minicepa ainda não se encontrar com sua formação ideal (com maior número de gemas com possibilidade de produzir miniestacas).

Os resultados relativos à alta sobrevivência e à produção de miniestacas em coletas sucessivas indicaram a viabilidade técnica do uso do sistema de jardim miniclonal adotado no presente estudo, visando a propagação de cedro-rosa por miniestaquia. Esses resultados concordam com os obtidos com Eucalyptus, conforme mencionado por Assis et al. (1992), Xavier \& Comério (1996), Wendling et al. (2000), para os quais a propagação vegetativa por miniestaquia é considerada viável.

Quanto ao enraizamento das miniestacas, foram avaliadas as três primeiras coletas, as quais foram submetidas a quatro tratamentos do regulador de crescimento AIB para enraizamento. Os dados obtidos na saída da casa de vegetação (ENRCV) e a sobrevivência das mudas aos 120 dias de idade (SOB120) indicaram melhores resultados na primeira e na terceira coleta (Figura 3).

É importante ressaltar que a segunda coleta de miniestacas foi realizada no período de temperatura mais baixa (média da temperatura ambiente em torno de $16^{\circ} \mathrm{C}$ ) em relação às demais coletas (média da temperatura ambiente em torno de $22{ }^{\circ} \mathrm{C}$ ), o que provavelmente proporcionou condições fisiológicas menos favoráveis ao processo de desenvolvimento e crescimento das brotações e, conseqüentemente, as miniestacas obtidas responderam negativamente ao processo de enraizamento. Esta possibilidade está de acordo com citações na literatura (Wilson, 1992; Paiva \& Gomes, 1995; Hartmann et al., 1997), que indicam, entre outros fatores, que as variações climáticas e as condições fisiológicas da planta-matriz influenciam o sucesso da propagação vegetativa por enraizamento de estacas.

Quanto ao efeito da aplicação do regulador de crescimento para enraizamento (AIB) sobre o enraizamento das miniestacas na saída da casa de vegetação (ENRCV) e a sobrevivência das mudas aos 120 dias de idade (SOB120), de modo geral, não houve influência significativa $(P>0,05$, pelo teste $F)$ das diferentes dosagens. Isto pode ser explicado, em parte, pelo fato de se tratar de material juvenil, no qual o balanço hormonal interno mostra-se favorável ao enraizamento, podendo ocorrer, em certas condições, resposta negativa às aplicações hormonais adicionais.

R. Árvore, Viçosa-MG, v.27, n.2, p.139-143, 2003 


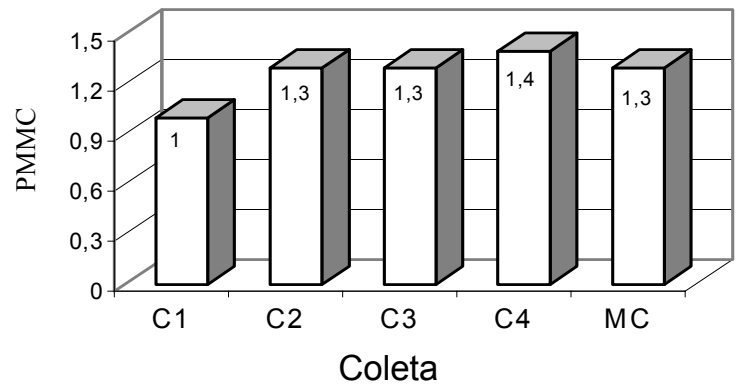

Figura 2 - Média de produção de miniestacas por minicepa por coleta (PMMC) de cedro-rosa (Cedrela fissilis) em quatro coletas sucessivas $(\mathrm{C} 1, \mathrm{C} 2, \mathrm{C} 3$ e $\mathrm{C} 4)$ e média das coletas (MC) realizadas no jardim miniclonal.

Figure 2 - Mean values of production from minicuttings by ministumps at each harvesting (PMMC) of cedro-rosa (Cedrela fissilis) in four successive harvestings (C1,C2, C3 $e$ C4) and mean of the harvestings (MC) in the miniclonal garden.

Segundo Hartmann et al. (1997), aplicações exógenas de reguladores de crescimento aos propágulos vegetativos, principalmente auxinas, proporcionam maior porcentual, velocidade e qualidade de enraizamento, embora as concentrações recomendadas variem em função da espécie, do estado de maturação, das condições ambientais, da forma de aplicação, entre outros fatores (Chung \& Lee 1994; Wilson 1994). Desta forma, considerando as condições experimentais e a juvenilidade das miniestacas utilizadas no presente estudo, tem-se a indicação de que o cedro-rosa apresenta aptidão natural ao enraizamento de miniestacas, não justificando a aplicação do regulador de crescimento para enraizamento.

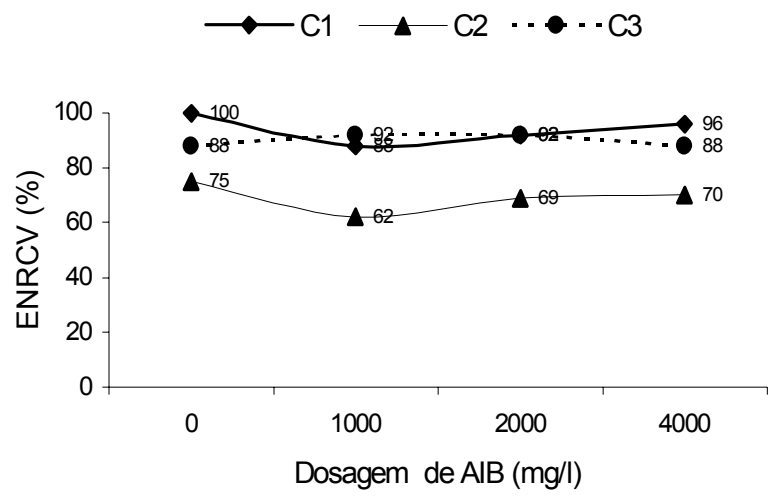

Os resultados obtidos para altura (ALT) e diâmetro do colo (DC) aos 120 dias de idade (Figura 4), de modo geral, confirmaram as inferências feitas a respeito do enraizamento das miniestacas na saída da casa de vegetação e da sobrevivência das mudas aos 120 dias, onde não houve influência significativa $(P>0,05$, pelo teste $F)$ da aplicação de AIB. Entre as coletas, os menores valores encontrados para a coleta 2 provavelmente estão relacionados à época de desenvolvimento e crescimento das brotações utilizadas na confecção das miniestacas, ou seja, no período de temperatura mais baixa. Neste ambiente, o propágulo vegetativo utilizado como miniestacas apresentava condições fisiológicas menos favoráveis ao processo de propagação vegetativa em relação às coletas 1 e 3 .

Vale salientar que no presente trabalho os gráficos foram elaborados a partir das médias das características, pois os coeficientes de determinação $\left(\mathrm{R}^{2}\right)$, na análise de regressão, apresentaram valores baixos, variando de 21 a $46 \%$, o que denota não-confiabilidade das equações de regressão para explicar as respostas das características avaliadas em função das aplicações de reguladores de crescimento.

Com base nesses resultados, conclui-se que a miniestaquia de cedro-rosa, a partir de material de origem seminal, é tecnicamente viável, tornando-se uma alternativa para produção de mudas desta espécie durante todo o ano, principalmente nas situações em que a semente é insumo limitante, ou para propagação de espécies com sementes de baixo índice de germinação ou de difícil

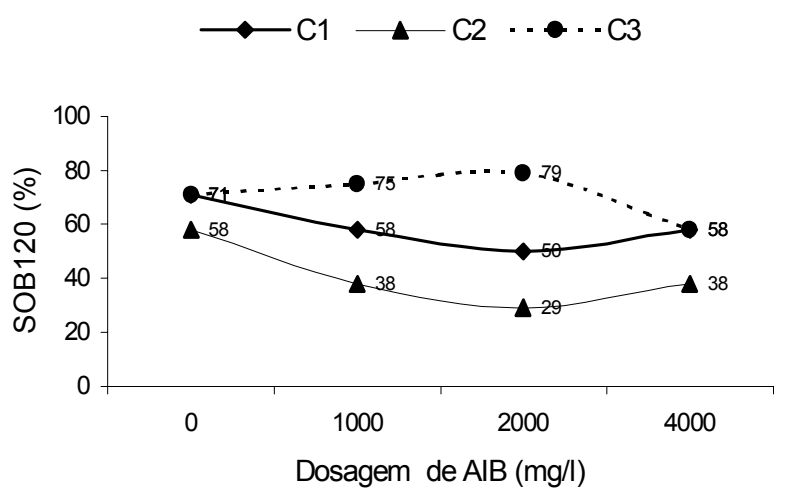

Figura 3 - Enraizamento das miniestacas de cedro-rosa (Cedrela fissilis) na saída da casa de vegetação (ENRCV) e sobrevivência das mudas aos 120 dias de idade (SOB120), em função da aplicação de diferentes dosagens de AIB (0, 1.000, 2.000 e $4.000 \mathrm{mg} / \mathrm{l})$, em três coletas $(\mathrm{C} 1, \mathrm{C} 2$ e C3).

Figure 3 - Rooting of the minicuttings of cedro-rosa (Cedrela fissilis) in the greenhouse exit (ENRCV) and survival at 120 days of age (SOB120), after application of different dosages of AIB (0, 1,000, 2,000 e 4,000 mg / l), in three harvestings (C1, C2 e C3).

R. Árvore, Viçosa-MG, v.27, n.2, p.139-143, 2003 

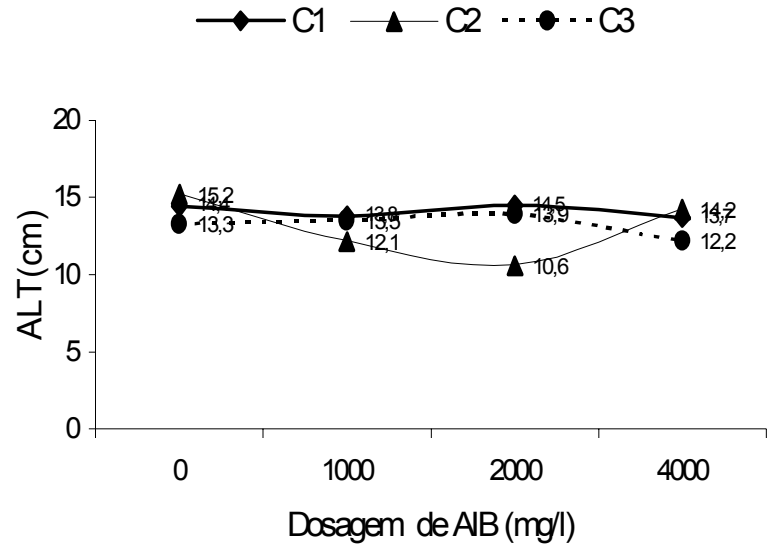
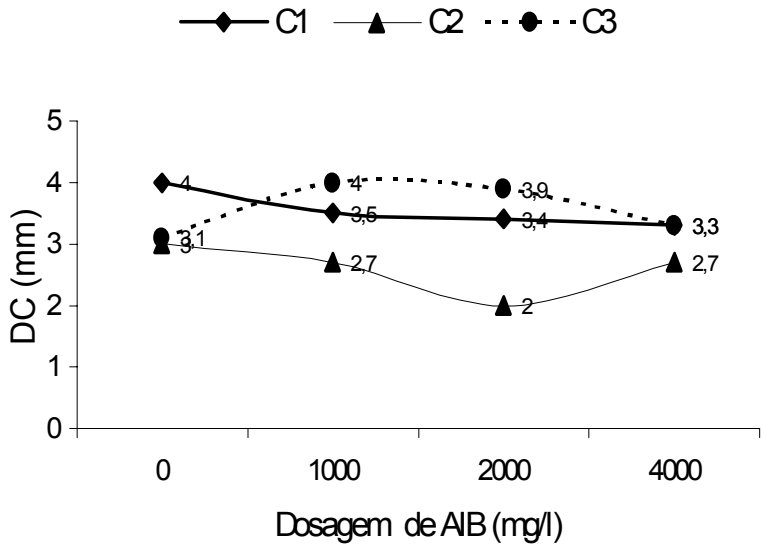

Figura 4 - Altura (ALT) e diâmetro do coleto (DC) das miniestacas enraizadas de cedro-rosa (Cedrela fissilis) aos 120 dias de idade, em função da aplicação de diferentes dosagens de $\operatorname{AIB}(0,1.000,2.000$ e $4.000 \mathrm{mg} / 1)$, das três coletas realizadas (C1, $\mathrm{C} 2$ e C3).

Figure 4 - Height (ALT) and root collar diameter (DC) of the minicuttings of cedro-rosa (Cedrela fissilis) at 120 days of age as a result of application of different dosages of $A I B(0,1,000,2,000$ e 4,000 $\mathrm{mg} / \mathrm{l})$, in three collections. (C1, C2 e C3).

armazenamento. Além disto, esta técnica constitui uma alternativa na propagação vegetativa de mudas oriundas de sementes provenientes de famílias selecionadas, maximizando a propagação de certas árvores-matriz.

\section{REFERÊNCIAS BIBLIOGRÁFICAS}

ASSIS, T. F.; ROSA, O. P.; GONÇALVES, S. I. Propagação por microestaquia. In: CONGRESSO FLORESTAL ESTADUAL, 7., 1992, Nova Prata. Anais . . . Santa Maria: Universidade Federal de Santa Maria, 1992. p. 824-836.

BLAZICH, F. A. Mineral nutrition and adventitious rooting. In: DAVIES, T. D.; HAISSIG, B. E.; SANKHLA, N. Adventitious root formation in cuttings. Portland: Dioscorides Press, 1987. p. 61-69 (Advances in Plant Sciences Series, 2).

CHALFUN, N. N. J. Fatores bioquímicos e fisiológicos no enraizamento de estacas de Hibiscus rosa-sinensis $\mathrm{L}$. 1989. 85 f. Tese (Doutorado em Fitotecnia) - Universidade Federal de Viçosa, Viçosa-MG, 1989.

CHUNG, D. Y.; LEE, K. J. Effects of clones, ortet age, crown position, and rooting substance upon the rooting of cuttings of Japanese larch (Larix leptolepis (Sieb. et Zucc.) Gordon). Forestry Genetics Research Institute, v. 83, n. 2, p. 205-210, 1994. (CD-ROM)
HARTMANN, H. T. et al. Plant propagation, principles and practices. 6.ed. New Jersey: Prentice-Hall, 1997. $770 \mathrm{p}$.

PAIVA, H. N.; GOMES, J. M. Propagação vegetativa de espécies florestais. Viçosa, MG: UFV, 1995. 40 p. (Boletim, 322).

SANTOS, G. A. et al. Enraizamento de miniestacas de Jequitibá rosa, Sete cascas e Mogno - Resultados preliminares. In: SIMPÓSIO DE INICIAÇÃO CIENTÍFICA DA UFV, 10., 2000, Viçosa. Anais... Viçosa: Universidade Federal de Viçosa, 2000. p. 63.

WILSON, P. J. The concept of a limiting rooting morphogen in woody stem cuttings. Journal of Horticultural Science, v. 9, n. 4, p. 391-400, 1994.

WENDLING, I. et al. Propagação clonal de híbridos de Eucalyptus spp. por miniestaquia. Revista Árvore, v. 24, n. 1, p. 181-186, 2000.

XAVIER, A.; COMÉRIO, J. Microestaquia: uma maximização da micropropagação de Eucalyptus. Revista Árvore, v. 20, n. 1, p. 9-16, 1996.

XAVIER, A.; WENDLING, I. Miniestaquia na clonagem de Eucalyptus. Viçosa-MG: SIF, 1998. 10 p. (Informativo Técnico SIF, 11).

R. Árvore, Viçosa-MG, v.27, n.2, p.139-143, 2003 